\title{
Phylogeny of the Order Bacillales inferred from 3' 16S rDNA and 5' 16S-23S ITS nucleotide sequences
}

\author{
Sabarimatou Yakoubou ${ }^{1,2}$, Dong $\mathrm{Xu}^{1}$, Jean-Charles Côté ${ }^{1 *}$ \\ ${ }^{1}$ Agriculture and Agri-Food Canada, Research Centre, Gouin Blvd, St-Jean-sur-Richelieu, Canada; *Corresponding Author: \\ Jean-Charles.Cote $@$,agr.gc.ca \\ ${ }^{2}$ Département des Sciences Biologiques, Université du Québec à Montréal, Succ.“Centre-Ville” Montréal, Canada
}

Received 16 April 2010; revised 20 May 2010; accepted 25 May 2010.

\begin{abstract}
A short 220 bp sequence was used to study the taxonomic organization of the bacterial Order Bacillales. The nucleotide sequences of the $3^{\prime}$ end of the 16S rDNA and the 16S-23S Internal transcribed spacer (ITS) were determined for 32 Bacillales species and strains. The data for 40 additional Bacillales species and strains were retrieved directly from Genbank. Together, these 72 Bacillales species and strains encompassed eight families and 21 genera. The 220 bp sequence used here covers a conserved $150 \mathrm{bp}$ sequence located at the 3 ' end of the 16S rDNA and a conserved $70 \mathrm{bp}$ sequence located at the 5 ' end of the 16S-23S ITS. A neighbor-joining phylogenetic tree was inferred from comparative analyses of all 72 nucleotide sequences. Eight major Groups were revealed. Each Group was sub-divided into sub-groups and branches. In general, the neighbor-joining tree presented here is in agreement with the currently accepted phylogeny of the Order Bacillales based on phenotypic and genotypic data. The use of this 220 bp sequence for phylogenetic analyses presents several advantages over the use of the entire 16S rRNA genes or the generation of extensive phenotypic and genotypic data. This 220 bp sequence contains $150 \mathrm{bp}$ at the $3^{\text {' end of the }}$ 16S rDNA which allows discrimination among distantly related species and $70 \mathrm{bp}$ at the 5 ' end of the 16S-23S ITS which, owing to its higher percentage of nucleotide sequence divergence, adds discriminating power among closely related species from same genus and closely related genera from same family. The method is simple, rapid, suited to large screening programs and easily accessible to most laboratories.
\end{abstract}

Keywords: Bacillales; 16S rDNA; 16S-23S ITS; Phylogeny

\section{INTRODUCTION}

In the 1st Edition of Bergey's Manual of Systematic Bacteriology (1986), the genus Bacillus, a member of the Class Bacilli, encompassed the Gram-positive, rodshaped, endospore-forming, either obligate or facultative aerobe bacteria [1]. A total of 34 species and 26 additional species incertae sedis were described. The genus was highly heterogeneous, exhibiting a wide range of nutritional requirements, physiological and metabolic diversity and DNA base composition. In the following two decades, numerical classifications [2], 16S rDNA sequence alignments [3], characterizations at the genotypic and phenotypic levels of selected Bacillus species, all led to the creation of several new genera (briefly reviewed in Xu and Côté [4]).

In 2003, we developed a method for the identification, classification and phylogenetic analyses of Bacillus species and species from closely related genera [4]. The method was simple, rapid, suited to large screening programmes and easily accessible to most laboratories. In summary, the method relied on comparisons of a $220 \mathrm{bp}$ nucleotide sequence marker among Bacillus species. This 220 bp marker was a combination of a $150 \mathrm{bp} \mathrm{se}-$ quence at the $3^{\prime}$ end of the 16S rRNA gene and a $70 \mathrm{bp}$ sequence at the 5 ' end of the 16S-23S ITS sequence. In our original study, a total of 40 species was analyzed. We showed that the phylogeny inferred from the $220 \mathrm{bp}$ marker was in agreement with then current classifications based on phenetic and molecular data, with exceptions. It revealed species and genera which appeared misassigned and for which additional characterization appeared warranted.

In the 2nd Edition of Bergey's Manual of Systematic Bacteriology [5], a new taxonomy of the Class Bacilli is 
presented. It is the result of phylogenetic and principal-component analyses of comprehensive datasets of 16S rDNA sequences [5,6]. The Bacillus genus belongs to the Order Bacillales. The Order Bacillales contains nine families: Alicyclobacillaceae, Bacillaceae, Listeriaceae, Paenibacillaceae, Pasteuriaceae, Planococcaceae, Sporolactobacillaceae, Staphylococcaceae and Thermoactinomycetaceae. All nine families contain a total of 51 genera.

Today, we further assess the usefulness of the $220 \mathrm{bp}$ marker by extending its analyses beyond the genus $B a$ cillus, to a higher taxa level, the Order Bacillales. Whereas our first study focused on species from the genus Bacillus and species from closely related genera [4], we report here the phylogenetic analyses of 72 species and strains from eight Bacillales families and 21 genera.

\section{MATERIALS AND METHODS}

\subsection{Bacterial Strains and Culture Conditions}

A total of 72 strains of the Order Bacillales were used in this study. These encompassed eight families, 21 genera and 67 species. A total of 31 Bacillales strains were obtained from the "Deutsche Sammlung von Mikroorganismen und Zellkulturen" (DSMZ) GmbH, Braunschweig, Germany and were grown according to the DSMZ guidelines (http://www.dsmz.de/microorganisms/media list. php). Jeotgalibacillus alimentarius was obtained from the "Czech Collection of Microorganisms" (CCM), Masaryk University, Brno, Czech Republic and grown according to the CCM guidelines (http://www.sci.muni. $\mathrm{cz} / \mathrm{ccm} /$ index.html). The nucleotide sequences of the 40 remaining strains were retrieved directly from GenBank. All bacterial strains and their sources are listed in Table 1.

Escherichia coli strain TOP10 (Invitrogen Inc., Burlington, ON, Canada) was used for cloning PCR fragments. Strain TOP10 was cultured on Luria-Bertani (LB) agar plates to select transformants or in LB broth to multiply the cells, with shaking at $180-200 \mathrm{rpm}$ at $37^{\circ} \mathrm{C}, 1 \mathrm{~h}$.

\subsection{DNA Extraction}

Bacterial cells were washed with TESS buffer $[10 \mathrm{mM}$ Tris/ $\mathrm{HCl}$ ( $\mathrm{pH}$ 8.0), $1 \mathrm{mM} \mathrm{Na} \mathrm{EDTA}_{2}, 0.1 \mathrm{M} \mathrm{NaCl}$ and $0.1 \%$ Sarkosyl ( $N$-lauroylsarcosine)] and resuspended in TE buffer [10 mM Tris/HCl (pH 8.0), 1 mM Na 2 EDTA]. Cells were lysed with $10 \mathrm{mg} / \mathrm{ml}$ lysozyme and $0.1 \%$ SDS. The subsequent phenol/chloroform extractions and ethanol precipitation were carried out as described by Sambrook and Russel [7].

Recombinant plasmid from E. coli strain TOP10 was isolated using the alkaline-lysis method [8] with some modifications as described elsewhere [4].

\subsection{Amplification of the 3' End 16S rDNA and the 16S-23S ITS Region}

A pair of primers: L516SF (5'-TCGCTAGTAATCGCGG ATCAGC-3') and L523SR (5'-GCATATCGGTGTTAG TCCCGTCC-3'), Reference [4] was used for the amplification of the 3 ' end of $16 \mathrm{~S}$ rDNA, the $16 \mathrm{~S}-23 \mathrm{~S}$ ITS region and the 5' end of $23 \mathrm{~S}$ rDNA. Amplification was performed in a Thermal Cycler 9600 (Perkin Elmer, Waltham, MA, USA) and the reaction mixtures contained $50 \mathrm{ng}$ template DNA, $0.25 \mu \mathrm{M}$ each primer, $200 \mu \mathrm{M}$ dNTP, $1.5 \mathrm{mM} \mathrm{MgCl}_{2}$ and 1.25 U Taq DNA polymerase (QIAGEN Inc. Mississauga, ON, Canada) in a final volume of $50 \mu \mathrm{l}$. PCR was performed under the following conditions: $45 \mathrm{~s}$ at $95^{\circ} \mathrm{C}$ and then 30 cycles of $15 \mathrm{~s}$ at $94^{\circ} \mathrm{C}, 30 \mathrm{~s}$ at $53^{\circ} \mathrm{C}$ and $90 \mathrm{~s}$ at $72^{\circ} \mathrm{C}$. Amplification products were visualized on agarose gels.

\subsection{Cloning and Sequencing Methods}

The amplified DNAs were cloned into a pCRII-TOPO cloning vector using the TOPO TA cloning kit (Invitrogen, Inc.), following the manufacturer's instructions. Escherichia coli strain TOP10 transformants were selected on LB agar plates containing kanamycin $(50 \mu \mathrm{g} / \mathrm{ml})$, 5-bromo-4-chloro-3-indolyl-beta-D-galacto-pyranoside (X-Gal) $(40 \mu \mathrm{g} / \mathrm{ml})$. Multiple clones were submitted for futher analyses for each Bacillales species. The recombinant plasmids were isolated using the modified alkaline-lysis method, digested with EcoRI and visualized on agarose gels to confirm the presence of an inserted fragment.

The nucleotide sequences of cloned fragments were determined by the dideoxynucleotide chain termination method [9], using a capillary array automated DNA sequencer (ABI 3730xl DNA analyzer; Applied Biosystems, Foster City, CA, USA). The sequences of both strands were determined.

\subsection{Sequence Analysis}

The 3' end of the 16S rDNA and the 16S-23S ITS of the 32 Bacillales species and strains sequenced in this study were used for analysis. Forty sequences publicly available from GenBank were added for comparison purposes to cover a wider range of Bacillales families and genera, for a total of 72 Bacillales species and strains. A neighbor-joining tree was constructed [10] based on the alignment of the $723^{\prime}$ end of the $16 \mathrm{~S}$ rDNA and the 5' end of the $16 \mathrm{~S}-23 \mathrm{~S}$ ITS sequences.

The tree was bootstrapped using 1,000 random samples of sites from the alignment, all using CLUSTAL W software [11] at the DNA Data Bank of Japan (DDBJ) (http://clustalw.ddbj.nig.ac.jp/top-e.html), with the Ki- 
Table 1. Bacillale families, genera, species and strains used to construct the bootstrapped neighbor-joining tree inferred from the 220 bp sequence, and shown in Figure 3.

\begin{tabular}{|c|c|c|c|c|c|}
\hline \multirow{2}{*}{ Families, genera and species } & \multirow{2}{*}{ Source/Strain } & \multicolumn{2}{|c|}{ GenBank accession no. } & \multirow{2}{*}{ Groups } & \multirow{2}{*}{ Sub-groups } \\
\hline & & This study* & Retrieved** & & \\
\hline \multicolumn{6}{|l|}{ Alicyclobacillaceae } \\
\hline \multicolumn{6}{|l|}{ Alicyclobacillus } \\
\hline acidocaldarius subsp.acidocaldarius & DSM 446 & EU723605 & & $\mathrm{V}$ & \multirow{6}{*}{ Ungrouped } \\
\hline acidocaldarius subsp. rittmannii & DSM 11297 & EU723607 & & $\mathrm{V}$ & \\
\hline acidoterrestris & DSM 3922 & EU723608 & & $\mathrm{V}$ & \\
\hline cycloheptanicus & DSM 4006 & EU723610 & & $\mathrm{V}$ & \\
\hline herbarius & DSM 13609 & EU723613 & & & \\
\hline hesperidum & DSM 12489 & EU723615 & & $\mathrm{V}$ & \\
\hline \multicolumn{6}{|l|}{ Bacillaceae } \\
\hline \multicolumn{6}{|l|}{ Amphibacillus } \\
\hline fermentum & DSM 13869 & EU723600 & & VIII & Ungrouped \\
\hline tropicus & DSM 13870 & EU723602 & & VIII & iii \\
\hline xylanus & DSM 6626 & EU723603 & & VIII & iii \\
\hline \multicolumn{6}{|l|}{ Anoxybacillus } \\
\hline flavithermus & WK1 & & СР000922 & VIII & Ungrouped \\
\hline \multicolumn{6}{|l|}{ Bacillus } \\
\hline clausii & & & AP006627 & VI & $\mathrm{i}$ \\
\hline subtilis & 168 & & AL009126 & VI & $\mathrm{i}$ \\
\hline thuringiensis & Al Hakam & & СР000485 & VI & ii \\
\hline thuringiensis var. konkukian & $97-27$ & & AE017355 & VI & ii \\
\hline weihenstephanensis & KBAB4 & & CP000903 & VI & ii \\
\hline \multicolumn{6}{|l|}{ Filobacillus } \\
\hline milensis & DSM 13259 & EU723621 & & Ungrouped & \\
\hline \multicolumn{6}{|l|}{ Geobacillus } \\
\hline caldoxylosilyticus & DSM 12041 & EU723625 & & I & \\
\hline kaustophilus & HTA426 & & BA000043 & I & \\
\hline kaustophilus & DSM 7263 & EU723629 & & I & \\
\hline stearothermophilus & DSM 22 & EU723631 & & I & \\
\hline subterraneus & DSM 13552 & EU723636 & & I & \\
\hline thermocatenulatus & DSM 730 & EU723638 & & I & \\
\hline thermodenitrificans & NG80-2 & & СР000557 & I & \\
\hline thermodenitrificans & DSM 465 & EU723643 & & I & \\
\hline thermoglucosidasius & DSM 2542 & EU723644 & & I & \\
\hline thermoleovorans & DSM 5366 & EU723648 & & I & \\
\hline uzenensis & DSM 13551 & EU723651 & & I & \\
\hline \multicolumn{6}{|l|}{ Gracilibacillus } \\
\hline dipsosauri & DSM 11125 & EU723655 & & VIII & \\
\hline halotolerans & DSM 11805 & EU723657 & & VIII & ii \\
\hline Halobacillus & & & & & \\
\hline$s p$ & SA-Hb6 & & AB367166 & VIII & $\mathrm{i}$ \\
\hline Oceanobacillus & & & & & \\
\hline iheyensis & HTE831 & & BA000028 & VIII & $\mathrm{i}$ \\
\hline Virgibacillus & & & & & \\
\hline marismortui & DSM 12325 & EU723664 & & VIII & ii \\
\hline pantothenticus & DSM 26 & EU723672 & & VIII & ii \\
\hline proomii & DSM 13055 & EU723675 & & VIII & ii \\
\hline salexigens & DSM 11483 & EU723666 & & VIII & ii \\
\hline Listeriaceae & & & & & \\
\hline Listeria & & & & & \\
\hline inoccua & Clip11262 & & AL592022 & VI & iii \\
\hline monocytogenes & EGD-e & & AL591824 & VI & iii \\
\hline elshimeri & SLCC5334 & & AM263198 & VI & iii \\
\hline Paenibacillaceae & & & & & \\
\hline Aneurinibacillus & & & & & \\
\hline aneurinilyticus & DSM 5562 & EU723616 & & III & i \\
\hline migulanus & DSM 2895 & EU723617 & & III & $\mathrm{i}$ \\
\hline thermoaerophilus & DSM 10154 & EU723618 & & III & $\mathrm{i}$ \\
\hline Brevibacillus & & & & & \\
\hline agri & ATCC 51360 & & AF478091 & III & ii \\
\hline borstelensis & ATCC 51668 & & AF478093 & III & ii \\
\hline brevis & ATCC8246 & & AY478094 & III & ii \\
\hline
\end{tabular}


Table 1. Continued.

\begin{tabular}{|c|c|c|c|c|c|}
\hline \multirow{2}{*}{ Families, genera and species } & \multirow{2}{*}{ Source/Strain } & \multicolumn{2}{|c|}{ GenBank accession no. } & \multirow{2}{*}{ Groups } & \multirow{2}{*}{ Sub-groups } \\
\hline & & This study* & Retrieved** & & \\
\hline brevis & NBRC10059 & & AP008955 & III & ii \\
\hline chosinensis & ATCC 51359 & & AF478095 & III & ii \\
\hline parabrevis & ATCC 8186 & & AF478097 & III & ii \\
\hline formosus & ATCC51669 & & AF478096 & III & ii \\
\hline \multicolumn{6}{|l|}{ Paenibacillaceae } \\
\hline \multicolumn{6}{|l|}{ Paenibacillus } \\
\hline alginolyticus & ATCC 51185 & & AF478104 & IV & \\
\hline alvei & ATCC 6344 & & AF478098 & IV & \\
\hline chondroitinus & ATCC 51184 & & AF478105 & IV & \\
\hline larvae & ATCC 9545 & & AF487106 & IV & \\
\hline lautus & ATCC 43898 & & AF487100 & IV & \\
\hline lentimorbus & ATCC 8244 & & AY763503 & IV & \\
\hline macerans & ATCC 43899 & & AF478101 & IV & \\
\hline pabuli & ATCC 14707 & & AF478102 & IV & \\
\hline popilliae & KLN 3 & & СР001656 & IV & \\
\hline$s p$ & JDR-2 & & DQ062684 & IV & \\
\hline validus & ATCC 43897 & & AF478103 & IV & \\
\hline \multicolumn{6}{|l|}{ Pasteuriaceae } \\
\hline \multicolumn{6}{|l|}{ Pasteuria } \\
\hline ramosa & P5 & & AY762091 & II & \\
\hline penetrans & CJ-1 & & AY123968 & II & \\
\hline \multicolumn{6}{|l|}{ Planococcaceae } \\
\hline \multicolumn{6}{|l|}{ Jeotgalibacillus } \\
\hline alimentarius & CCM 7134 & EU723660 & & VI & \\
\hline \multicolumn{6}{|l|}{ Marinibacillus } \\
\hline \multirow{2}{*}{\multicolumn{6}{|c|}{ Ureibacillus }} \\
\hline & & & & & \\
\hline terrenus & DSM 12654 & EU723667 & & VI & iv \\
\hline thermosphaericus & DSM 10633 & EU723670 & & VI & iv \\
\hline \multicolumn{6}{|l|}{ Sporolactobacillaceae } \\
\hline \multicolumn{6}{|l|}{ Sporolactobacillus } \\
\hline terrae & M-116 & & D16289.1 & Ungrouped & \\
\hline \multicolumn{6}{|l|}{ Staphylococcaceae } \\
\hline \multicolumn{6}{|l|}{ Staphylococcus } \\
\hline aureus & RF122 & & AJ938182 & VII & \\
\hline arnosus & TM300 & & AM295250 & VII & \\
\hline epidermidis & RP62A & & СР000029 & VII & \\
\hline haemolyticus & JCSC1435 & & AP006716 & VII & \\
\hline aprophyticus & ATCC 15305 & & AP008934 & VII & \\
\hline \multicolumn{6}{|l|}{ Macrococcus } \\
\hline caseolyticus & JCSC5402 & & AP009484 & VII & \\
\hline
\end{tabular}

*Sequences generated in this study; **Sequences publicly available in GenBank at the onset of this work and retrieved directly.

mura's parameter method [12]. The neighbor-joining phylogenetic tree was drawn using TreeView (version 1.6.6) $[13,14]$.

\section{RESULTS}

Two primers, one located about 200 nt upstream from the 3 ' end of the $16 \mathrm{~S}$ rRNA gene, the other about $80 \mathrm{nt}$ downstream from the 5 ' end of the 23S rRNA gene (Figure 1), were used to amplify the last $200 \mathrm{bp}$ of the $16 \mathrm{~S}$ rRNA gene and the entire 16S-23S Internal transcribed spacer (ITS) region from 32 Bacillales species and strains (Table 1). The amplicons ranged in length from 450 to $1,200 \mathrm{bp}$. The number of amplicons per strain ranged from 1 to 6 . A subset of these results is shown in Figure 2. Each amplicon was cloned and its nucleotide sequence determined. The homologous DNA sequences from 40 more Bacillales species and strains were retrieved directly from GenBank and added in the study (Table 1). Together, these 72 Bacillales species and strains belong to eight Bacillales families and 21 genera.

The last $150 \mathrm{bp}$ located at the 3' end of 16S rDNA and the first $70 \mathrm{bp}$ located at the 5' end of $16 \mathrm{~S}-23 \mathrm{~S}$ ITS, were combined into a $220 \mathrm{bp}$ sequence. A multiple alignment of these nucleotide sequences from the 72 Bacillale species and strains was performed (supplementary data) and a bootstrapped neighbor-joining tree was constructed (Figure 3). 


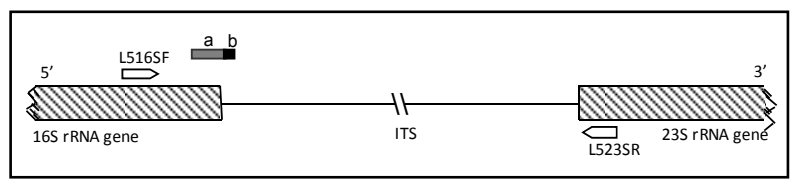

Figure 1. Schematic representation of the $16 \mathrm{~S}$ and $23 \mathrm{~S}$ rRNA genes separated by an Internal transcribed spacer (ITS). Orientations and positions of the primers used for amplification, L516SF and L523SR, are shown. The contiguous small grey and black boxes, indicated by the letters "a" and "b" correspond to the last $150 \mathrm{bp}$ at the 3' end of the 16S rRNA gene and the first $70 \mathrm{bp}$ at the 5 ' end of the ITS, respectively. Together, these boxes correspond to the 220 bp marker used in this study.

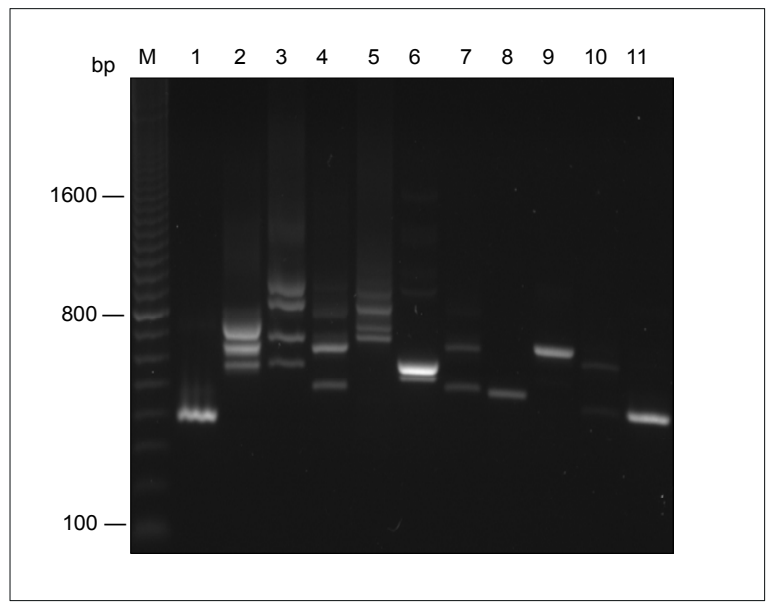

Figure 2. Agarose gel electrophoresis of the amplification products in selected species in the Order Bacillales using the L516SF/L523SR primer pair. Lane 1, 100 bp DNA marker; lane 2, Alicyclobacillus acidocaldarius subsp. acidocaldarius; lane 3, Alicyclobacillus herbarius; lane 4, Geobacillus uzenensis; lane 5, Gracilibacillus halodurans; lane 6, Geobacillus kaustophilus; lane 7, Amphibacillus tropicus; lane 8, Virgibacillus proomii; lane 9, Virgibacillus salexigens; lane 10, Marinibacillus marinus; lane 11, Aneurinibacillus aneurinilyticus ; lane 12, Filobacillus milensis.

At first sight, eight major Groups are revealed at the $80 \%$ nucleotide sequence identities, Group I to VIII. Group I contains all eleven Geobacillus species and strains. Alicyclobacillus herbarius forms a single branch between Groups I and II. Group II contains both Pasteuriaceae species. Group III contains ten species and strains from two genera of the Paenibacillaceae family. Two sub-groups can be revealed. Sub-group i encompasses the three Aneurinibacillus species. They share at least $82 \%$ nucleotide sequence identities. Sub-group ii encompasses the seven Brevibacillus species and strains. They share at least $80 \%$ nucleotide sequence identities. Group IV contains all 11 Paenibacillus species. Group V contains five of the six species and strains in the Alicyclobacillaceae family. Alicyclobacillus herbarius is the sixth species, and forms a single branch as explained above, because it shares less than $80 \%$ nucleotide sequence identities with members of Group V. Group VI is more heterogenous. It contains 12 species and strains from five genera from three families: the Planococcaceae, Bacillaceae and Listeriaceae. Four sub-groups and two branches are revealed. Jeotgalibacillus alimentarus forms the first branch of Group VI, and belongs to the Planococcaceae family. Sub-group i contains two $B a$ cillus species of the Bacillaceae family, B. clausii and $B$. subtilis. Marinibacillus marinus forms the second branch of Group VI. It is the second genus of the Planococcaceae family. Sub-group ii contains three highly related Bacillus species and strains, the two B. thuringiensis strains and $B$. weihenstephanensis. Sub-group iii contains all three Listeria species of the Listeriaceae family. Sub-group iv contains both species of the third Planococcaceae genus, Ureibacillus. Next, a branch is formed by Sporolactobacillus terrae. This genus is the only one known in the Sporolactobacillaceae family. This is followed by a branch formed by Filobacillus milensis, a member of the Bacillaceae family. Group VII contains five Staphylococcus and one Macrococcus species. Both genera belong to the Staphylococcaceae family. Group VIII contains 12 species from six genera, all in the $\mathrm{Ba}$ cillaceae family. Three subgroups and thee branches can be revealed. Sub-group i contains Oceanobacillus and Halobacillus. They share $87 \%$ nucleotide sequence identities. The grouping of Oceanobacillus and Halobacillus species in sub-group $i$ is in agreement with the work of Lu et al., properties, and genetic data [15]. Sub-group ii contains five species from two genera. It can be further divided into two clusters. The first one contains Virgibacillus (V.) pantothenticus, V. proomii and Gracilibacillus halotolerans, the second cluster contains $V$. marismortui and $V$. salexigens. The subdivision of all four Virgibacillus species into two sub-groups is in agreement with the work of Heyrman et al., based on genetic, chemotaxonomic and phenotypic data [16]. Sub-group iii contains two of the three Amphibacillus (Am.) species, Am. xylanus and Am. tropicus. Group VIII is completed by three branches: Gracilibacillus dipsosauri, Anoxybacillus flavithermus and Amphibacillus fermentum. All members of Group VIII are halophilic and alkaliphilic bacilli. This grouping is in agreement with the one proposed by Zhilina et al., based on physiology and genetic data [17].

When each of the eight major Groups of this neighborjoining tree are analyzed separately, strains from same species, species from same genus and genera from same family are grouped together. Each Group corresponds to a single Bacillales family, exclusive of other families, with one exception, Group VI which contains three fami- 


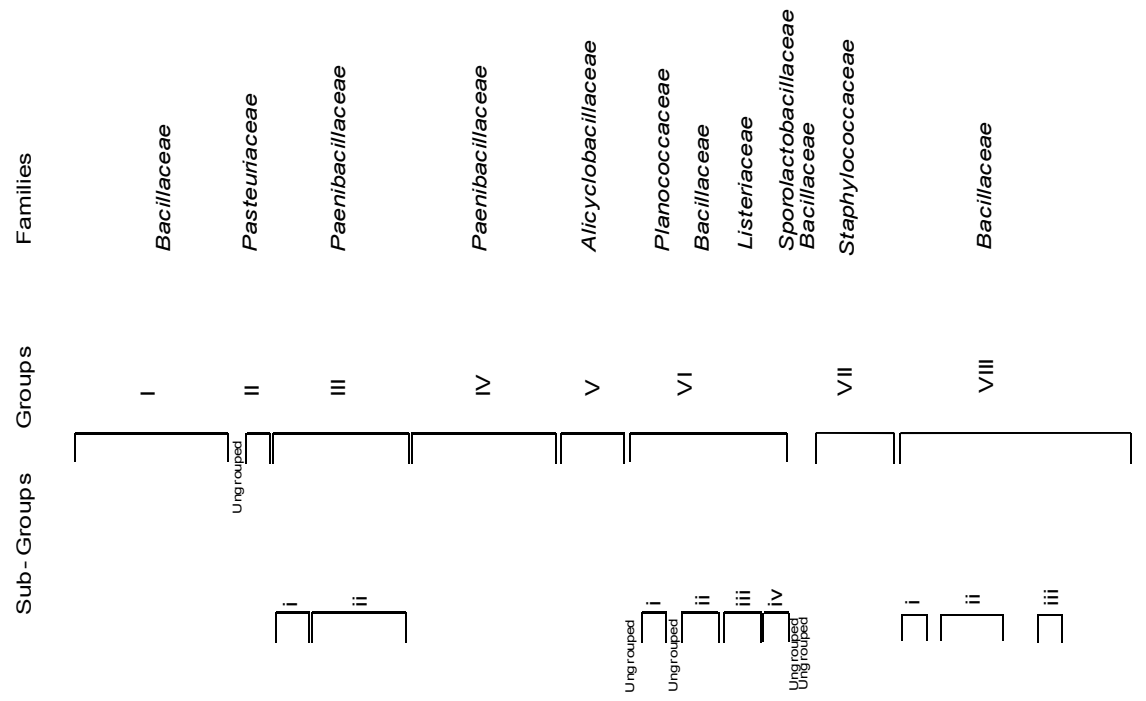

$\frac{\frac{n}{4}}{\frac{D}{0}}$

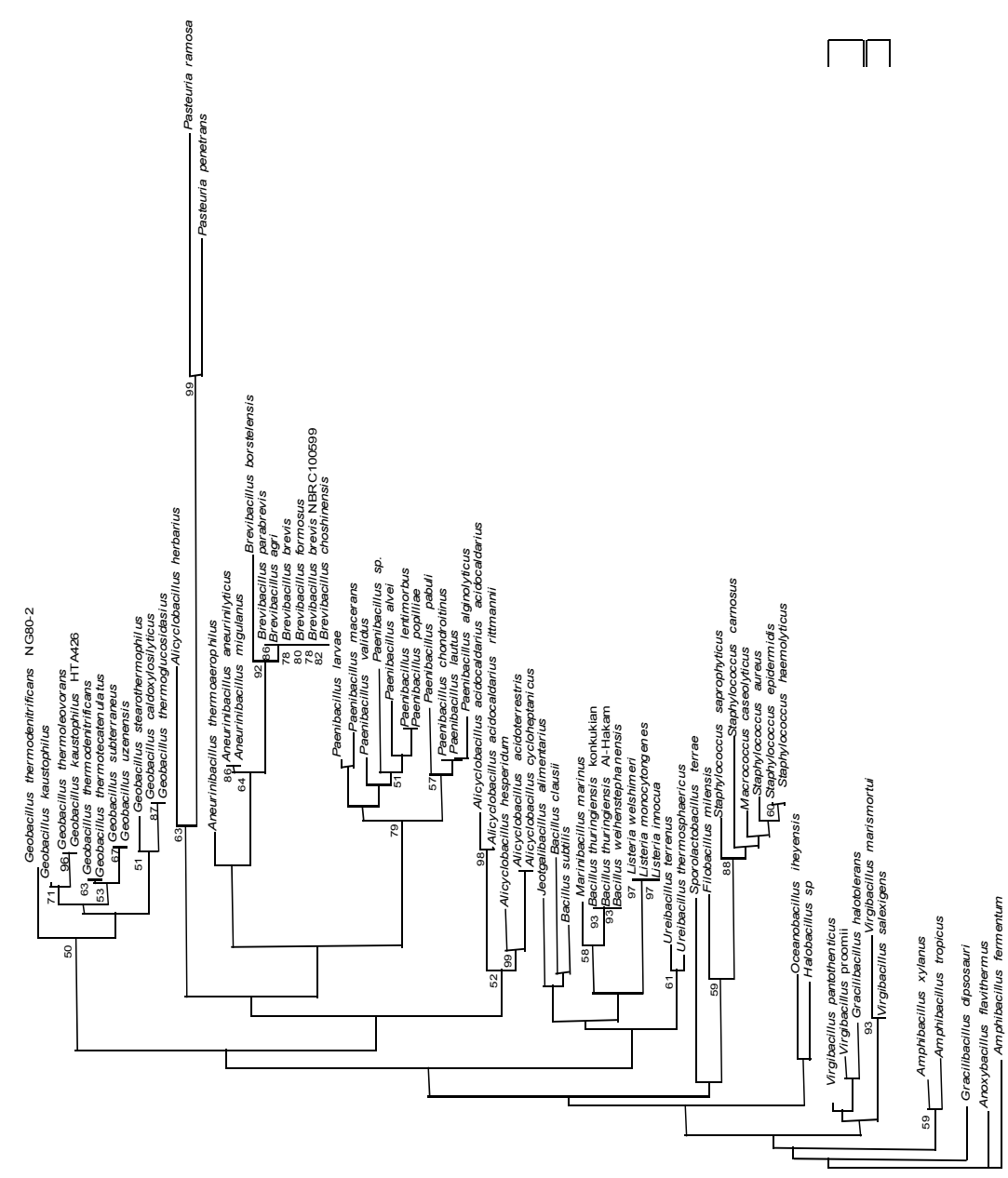

Figure 3. Bootstrapped neighbor-joining tree of 72 Bacillales species and strains inferred from the alignment of the 220 bp marker. Major Groups are indicated in capital roman numerals. Sub-groups are indicated in lower case riman numerals. Bootstrap values higher than $50 \%$ are indicated (expressed as percentage of 1000 replication). The horizontal bar represents $1 \% \mathrm{nt}$ difference. 
lies. In some cases, Groups were divided into sub-groups which corresponded to genera, with one exception, Group VIII where sub-groups encompassed different genera. The family Sporolactobacillaceae forms a branch between Groups VI and VII. Three Bacillales families: Bacillaceae, Paenibacillaceae and Alicyclobacillaceae, show some level of heterogeneity. Genera of the Bacillaceae family are found into three Groups, Groups I, VI and VIII, and in a branch between Groups VI and VII. Genera of the Paenibacillaceae family are found into two Groups, Groups III and IV. Analysis of the Alicyclobacillaceae family reveals a different story. Five of the six species and strains are clustered together in Group V. The sixth, Alicyclobacillus herbarius, is more distant. It forms a branch between Groups I and II. This is in agreement with the work of Goto et al. [18]. Although distinct from all other Alicyclobacillaceae based on genomic data, including $16 \mathrm{~S}$ rDNA sequences, Alicyclobacillus herbarius was grouped with the family based on the presence of $\omega$-cycloheptane fatty acids [18].

\section{DISCUSSION}

In a 2003 study [4], on Bacillus and closely-related genera, a multiple alignment of the 3 ' end of the $16 \mathrm{~S}$ rRDA sequence showed that the last 157 nucleotides shared extensive identities among closely related species from same genus. This 157 nucleotide sequence, however, was not conserved among species from different genera. In the same study, a multiple alignment of the $16 \mathrm{~S}-23 \mathrm{~S}$ Internal transcribed spacer (ITS) sequence showed that the first 70 nucleotides were conserved between alleles of the same strain and between alleles of different strains from same species. This sequence, however, was not conserved among alleles of different species of the same genus. These two sequences, the last $150 \mathrm{bp}$ at the 3 ' end of the 16S rRNA gene and the first $70 \mathrm{bp}$ at the 5 ' end of the $16 \mathrm{~S}-23 \mathrm{~S}$ rRNA ITS, were combined into a single 220 bp marker. This marker was used to infer the phylogeny of Bacillus species and species from closely related genera. It could cluster Bacillus species and species from closely related genera into taxa akin to genera and could also distinguish closely related species. In this 2003 study, a total of 40 species was analyzed.

In the current study, we further assessed the usefulness of the $220 \mathrm{bp}$ marker at a higher taxonomic level, the Order Bacillales. A total of 72 Bacillales species and strains from eight Bacillales families and 21 genera were covered. The number of Bacillus species included in this current study on Bacillales was deliberately kept low since this genus had already been covered extensively in our earlier study [4]. The neighbor-joining tree presented here was compared with the revised road map of the
Order Bacillales shown in the 2nd Edition of Bergey's Manual of Systematic Bacteriology [5]. This revised road map [5] is a consensus phylogenetic tree of the Order Bacillales. It is the consensus tree inferred from numerous phylogenetic and principal-component analyses of comprehensive datasets of $16 \mathrm{~S}$ rDNA sequences [5,6]. Our phylogenetic tree presented here is in agreement with the currently accepted phylogeny of the Order $B a$ cillales, based on phenotypic and genotypic data. It is, in general, in agreement with the revised road map of the Order Bacillales [5]. In addition, some bacterial species that were not grouped at the genus level in our neighborjoining tree, exemplified by Alicyclobacillus herbarius, were also confirmed by others to be different based on phenotypic and genotypic data [18].

The main discrepancy between our results, obtained with the $220 \mathrm{bp}$ marker, and the revised road map shown in the 2nd Edition of Bergey's Manual of Systematic Bacteriology [5], rests on the grouping of the Bacillaceae family. In our study, members of the Bacillaceae family are present in three of the eight Groups. In the revised road map [5], two major Bacillaceae groups are presented. It is recognized, however, that some species have been misassigned to the Bacillaceae family [5]. The revised road map is constructed based on $16 \mathrm{~S}$ rDNA sequences [5]. Our $220 \mathrm{bp}$ marker contains $150 \mathrm{bp}$ from $16 \mathrm{~S}$ rDNA and $70 \mathrm{bp}$ from ITS. Owing to its higher rate of nucleotide substitutions, this $70 \mathrm{bp}$ adds discriminating power among species from same genera and genera from same family. As indicated by Ludwig et al. [5], and as shown here, the reorganization of the Bacillaceae family is still a work in progress.

The use of this $220 \mathrm{bp}$ marker presents several advantages over the use of the entire 16S rRNA gene or the generation of extensive phenotypic and genotypic data in phylogenetic analyses. As shown in an earlier study [4], the method is simple, rapid, suited to large screening programmes and easily accessible to most laboratories. We have shown here that it can group Bacillales families and genera in accordance with established phylogenies. Because the 220 bp marker shows a higher percentage of nucleotide sequence divergence than the 16S rRNA gene, it can better discriminate among closely related $\mathrm{Ba}$ cillales species. It can also reveal Bacillales species which may appear misassigned and for which additional characterization appear warranted.

In conclusion, in an earlier study [4], a $220 \mathrm{bp}$ marker, based on $3^{\prime}$ end of $16 \mathrm{~S}$ rRDA and 5' end of $16 \mathrm{~S}-23 \mathrm{~S}$ rRNA ITS, was developed and used to classify species in the Bacillus genus and in closely related genera. Here, we showed that this $220 \mathrm{bp}$ marker could be used to reconstruct the phylogeny at a higher taxa level: the Order Bacillales. We are planning to follow-up this work by 
assessing the resolving power of this marker in reconstructing the phylogeny at a lower taxa level: the Bacillus cereus group, sensu lato.

Recently, in parallel, a similar maker was tested and shown to be able to reconstruct the phylogeny of the Class $\gamma$-proteobacteria [19].

\section{REFERENCES}

[1] Claus, D. and Berkeley, R.C.W. (1986) Genus Bacillus Cohn, 1872. In: Sneath, P.H.A., Mair, N.S., Sharpe, M.E. and J.G. Holt., Ed., Bergey's Manual of Systematic Bacteriology, The Williams \& Wilkins Co., Baltimore, 2, 1105-1139.

[2] Priest, F.G., Goodfellow, M. and Todd, C. (1988) A numerical classification of the genus Bacillus. Journal of General Microbiology, 134(7), 1847-1882.

[3] Ash, C., Farrow, A.E., Wallbanks, S. and Collins, M.D. (1991) Phylogenetic heterogeneity of the genus Bacillus revealed by comparative analysis of small-subunit-ribosomal RNA sequences. Letters in Applied Microbiology, 13(4), 202-206.

[4] Xu, D. and Côté, J.-C. (2003) Phylogenetic relationships between Bacillus species and related genera inferred from comparison of 3' end 16S rDNA and 5' end 16S-23S ITS nucleotide sequences. International Journal of Systematic and Evolutionary Microbiology, 53, 695-704.

[5] Ludwig, W., Schleifer, K-H. and Whitman, W.B. (2009) Revised road map to the phylum Firmicutes. In: De Vos, P., et al. Eds., Bergey's Manual of Systematic Bacteriology, 2nd Edition, The Firmicutes, Springer-Verlag, New York, 3, 1-17.

[6] Garrity, G.M., Bell, J.A. and Lilburn, T. (2005) The Revised Road Map to the Manual. In: Brenner, D.J., Krieg, N.R., Staley, J.T. and Garrity, G.M., Eds., Bergey's Manual of Systematic Bacteriology, 2nd Edition, The Proteobacteria, Part A, Introductory Essays. Springer, New York, 2, 159-220.

[7] Sambrook, J. and Russell, D.W. (2001) Molecular Cloning: A Laboratory Manual. 3rd Edition, Cold Spring Harbor Laboratory Press, N.Y..

[8] Stephen, D., Jones, C. and Schofield, J.P. (1990) A rapid method for isolating high quality plasmid DNA suitable for DNA sequencing. Nucleic Acids Research, 18(24), 7463-7464

[9] Sanger, F., Nicklen, S. and Coulson, A.R. (1977) DNA sequencing with chain-termination inhibitors. Proceedings of the National Academy of Sciences, USA, 74, 5463-5467.

[10] Saitou, N. and Nei, M. (1987) The neighbor-joining method: A new method for reconstructing phylogenetic trees. Molecular Biology and Evolution, 4(4), 406-425.

[11] Thompson, J.D., Higgins, D.G. and Gibson, T.J. (1994) CLUSTAL W: Improving the sensitivity of progressive multiple sequence alignment through sequence weighting, positions-specific gap penalties and weight matrix choice. Nucleic Acids Research, 22(22), 4673-4680.

[12] Kimura, M. (1980) A simple method for estimating evolutionary rate of base substitutions through comparative studies of nucleotide sequences. Journal of Molecular Evolution, 16(2), 111-120.

[13] Page, R.D.M. (1996) TreeView: An application to display phylogenetic trees on personal computers. Computer Application in the Biosciences, 12(4), 357-358.

[14] Page, R.D.M. (2000) TreeView-tree drawing software for Apple Macintosh and Windows. http://taxonomy.zoology.gla.ac.uk/rod/treeview.html

[15] Lu, J., Nogi, Y. and Takami, H., (2001) Oceanobacillus iheyensis gen. nov., sp. nov., a deep-sea extremely halotolerant and alkaliphilic species isolated from a depth of $1050 \mathrm{~m}$ on the Iheya Ridge. FEMS Microbiology Letters, 205(2), 291-297.

[16] Heyrman, J., Logan, N.A., Busse, H.J., Balcaen, A., Lebbe, L., et al. (2003) Virgibacillus carmonensis sp. nov., Virgibacillus necropolis sp. nov. and Virgibacillus picturae sp. nov., three novel species isolated from deteriorated mural paintings, transfer of the species of the genus Salibacillus to Virgibacillus, as Virgibacillus marismortui comb. nov. and Virgibacillus salexigens comb. nov., and emended description of the genus Virgibacillus. International Journal of Systematic and Evolutionary Microbiology, 53, Part 2, 501-511.

[17] Zhilina, T.N., Garnova, E.S., Tourova, T.P., Kostrikina, N.A. and Zavarzin, G.A., (2001) AmAmphibacillus fermentum sp. nov. and Amphibacillus tropicus sp. nov., new alkaliphilic, facultatively anaerobic, saccharolytic bacilli from Lake Magadi. Mikrobiologiya, in Russian, 70(6), 825-837. English Translation: Microbiology, 70(6), $711-722$

[18] Goto, K., Matsubara, H., Mochida, K., Matsumura, T., Hara, Y., et al. (2002) Alicyclobacillus herbarius sp. nov., a novel bacterium containing omega-cycloheptane fatty acids, isolated from herbal tea. International Journal of Systematic and Evolutionary Microbiology, 52(1), 109113.

[19] Yakoubou, S. and Côté, J.-C. (2010) Phylogeny of $\gamma$-proteobacteria inferred from comparisons of 3' end $16 \mathrm{~S}$ rRNA gene and 5' end 16S-23S ITS nucleotide sequences. Natural Science, 2(6), 535-543. 